môn lâm sàng chẩn đoán và điều trị ĐTĐ nói riêng tại TTYT huyện Tứ Kỳ, tỉnh Hải Dương.

\section{TÀl LIÊU THAM KHẢO}

1. Vũ Thị Tuyết Mai (2011), "Thực trạng công tác quản lý điều trị bênh ĐTĐ týp 2 tại Trung tâm $Y$ tế huyện Gia Lâm nẳm 2011", Luận văn thạc sĩ Quản lý Bệnh viện, Trường Đai học Y tễ Công Cộng.

2. Phạm Văn Sang (2017), "Thực trang quản lý và điêu trị người bệnh ĐTĐ týp 2 tại Bệnh viện đa khoa Tứ Kỳ, Hải Dương năm 2017", Luận văn BSCK II, Trướng Đại học Y Thái Bình.

3. Hoàng Thị Đợi, Ngưyến Kim Lương (2015), "Nghiên cứu thực trang bệnh ĐTĐ týp 2 đang điều trị ngoại trú tại Bệnh viện Đa khoa Trung ương Thái Nguyên; Hội nghi khoa học toàn quốc chuyên ngành nội tiết và chuyển hoá lần thứ 3", tr. 900-911.

4. Vố Bảo Dũng (2008), "Nghiên cứu một số đặc điểm lâm sàng, cận lâm sàng và kết quả điều trị người bệnh ĐTĐ tại Bệnh viện Đa khoa tỉnh Bình Định" Tạp chí Y hoc thực hành, $(616$ + 617), tr. 267-273.

5. Hoàng Thị Hẳng và cống sự (2010), "Thực trang điêu trị bệnh ĐTĐ điểu trị tại khoa Nội Bệnh viển Đa khoa Bắc Kạn", Kỷ yếu các đề tài nghiên cứu khoa học - Bệnh viện Đa khoa Bắc Kạn.

6. Phạm Thu Hiền (2017), "Thực trạng việc thực hiện quy trình lấy máu tĩnh mạch của Điều dưỡng viển tại Bệnh viện Nhi trung ương năm 2017", Luận văn Thạc sî́ quản lý Bệnh viện, Trường Đại học Y tế Công Cộng.

7. Diana Ruchugo (2015), "Knowledge, Attitude and Practices of Type Two Diabetes in a Rural Community in Karatina-Nyeri Country", University of Nairobi, pp: 1-101.

8. Gunggu A, Thon CC, Whye Lian C. Predictors of Diabetes Self-Management among Type 2 Diabetes Patients. J Diabetes Res. 2016;2016:915894, Epub 2016 Aug 3. PMID: 27563681.

\title{
NHŨ̃NG YẾU TỐ ẢNH HƯỞNG ĐẾN KÍCH THƯớC NHĨ TRÁI TRÊN SIÊU ÂM TIM 3D Ở BỆNH NHÂN RUNG NHĨ KHÔNG DO BỆNH VAN TIM
}

\section{TÓM TẮT}

Giãn nhĩ trái là một yếu tố nguy cơ của đột quy và là yếu tố quyết định cho sự thành công của chiến lược kiểm soát nhịp tim ở bệnh nhân rung nhĩ. Tuy nhiên, những yếu tổ liễ̂n quan đến thể tích nhĩ trái ở bệnh nhân rung nhĩ vẫn chưa được hiểu đầy đủ. Mục tiều: Tìm hiểu những yếu tố liên quan đến giãn nhĩ trái trên siêu âm tim 3D ở bệnh nhân rung nhĩ không do bệnh van tim. Đối tượng và phương pháp: Nghiên cứu mô tả cắt ngang tiến hành trên các bệnh nhân rung nhĩ không do bệnh van tim. Tất cả các bệnh nhân được hỏi bệnh, thịăm khám lấm sàng kỹ lưỡng và làm bệnh án theo mẫu, làm một số thăm dò và xét nghiệm sinh hoá, làm ĐTĐ 12 chuyển đạo, làm siêu âm tim 2D và $3 \mathrm{D}$ theo hướng dẫn của Hội Siêu âm Tim Hoa Kỳ. Thể tích nhĩ trái được đánh giá trên siêu âm tim 3D bằng phân mềm Heart Model. Kết quả: Từ 07/2020 đến $07 / 2021$ có 80 bệnh nhân được đưa vào nghiên cứu, tuổi trung bình60,7 \pm 4,8, nam 48.8\%, nữ $51.2 \%$. Thể tích nhĩ trái trên siêu âm tim 3D có mối liên quan với các yếu tố như tiền sử tăng huyết áp $\left(\beta=1,3 \pm 0,9 \mathrm{ml} / \mathrm{m}^{2}\right)$, đái tháo đường $(\beta=0,8 \pm$ $\left.0,2 \mathrm{ml} / \mathrm{m}^{2}\right)$, bệnh thận mạn $\left(\beta=2,4 \pm 0,9 \mathrm{ml} / \mathrm{m}^{2}\right)$, bệnh mạch vành $(\dot{\beta}=2,2 \pm 0,5)$ và rối loạn chức năng tâm trương $\left(\beta=2,3 \pm 4,6 \mathrm{ml} / \mathrm{m}^{2}\right)$. Khi phân tích đa biến, bệnh mạch vành $\left(\beta=2,5 \pm 0,4 \mathrm{ml} / \mathrm{m}^{2}\right)$, bệnh thận mạn $\left(\beta=2,9 \pm 0,3 \mathrm{ml} / \mathrm{m}^{2}\right)$ và rối loạn chức năng tầm trương thất trái $\left(\beta=2,4 \pm 0,4 \mathrm{ml} / \mathrm{m}^{2}\right)$ cho thấy mối liên

*Viện Tim Mạch, Bênh Viện Bạch Mai.

Chịu trách nhiệm chính: Đỗ Doãn Bách

Email: dodoanbach@gmail.com

Ngày nhận bài: 7.9.2021

Ngày phản biện khoa học: 25.10.2021

Ngày duyệt bài: 8.11.2021

\section{Đỗ Doãn Bách*, Nguyễn Thị Thu Hoài*}

quan độc lập với thể tích nhĩ trái ở bệnh nhân rung nhĩ không do bệnh van tim. Kết luận: Rối loạn chức năng tâm trương thất trái, bệnh thận mạn, bệnh mach vành là những yếu tố có ảnh hưởng đển giẩn thể tích nhĩ trái trên siêu âm tim 3D ở các bệnh nhân rung nhĩ không do bệnh van tim. trái

Tư khóa: Rung nhĩ, siêu âm tim 3D, thể tích nhĩ

\section{SUMMARY}

\section{FACTORS AFFECTING LEFT ATRIAL SIZE ONTHREE-DIMENSIONAL ECHOCARDIOGRAPHY IN PATIENTS WITH NON-VALVULAR ATRIAL FIBRILLATION}

Background: Left atrial (LA) enlargement is an important risk factor for incident stroke and a key determinant for the success of rhythm control strategies in patients with atrial fibrillation (AF). However, factors associated with LA volume in AF patients remain poorly understood. Objective: To study factors related to left atrial dilation in patients with non-valvular atrial fibrillation on 3D echocardiography. Methods: A cross-sectional descriptive study was conducted in patients with nonvalvular atrial fibrillation. Data of medical history, clinical examination biochemical tests, ECG were collected. 2D and 3D echocardiography were performed in all participants and analyzed in a standardized manner. Left atrial volume was assessed on 3D echocardiography using Heart Model software. Results: From 07/2020 to 07/2021, 80 patients were included in the study, the mean age was $60.7 \pm 4.8$, male $48.8 \%$, female $51.2 \%$. Hypertension, diabetes mellitus, chronic kidney disease, coronary artery diseaseandleftventriculardiastolicdysfunction were 
associated with LA dilation on 3D echocardiography ( $\beta=1.3 \pm 0.9 \mathrm{ml} / \mathrm{m}^{2}, \beta=0.8 \pm 0.2 \mathrm{ml} / \mathrm{m}^{2}, \beta=2.4 \pm 0.9$ $\left.\mathrm{ml} / \mathrm{m}^{2}, \beta=2.2 \pm 0.5 \mathrm{ml} / \mathrm{m}^{2}, \beta=2,3 \pm 4.6 \mathrm{ml} / \mathrm{m}^{2}\right)$. In multivariable analysis:Coronary artery disease, chronic kidney disease, left ventricular diastolic dysfunctionshowed an independent association with left atrial volume in patients with non-valvular atrial fibrillation $\left(\beta=2,5 \pm 0,4 \mathrm{ml} / \mathrm{m}^{2}, \beta=2,9 \pm 0,3 \mathrm{ml} / \mathrm{m}^{2}\right.$, $\beta=2,4 \pm 0,4 \mathrm{ml} / \mathrm{m}^{2}$, respectively). Conclusion: Left ventricular diastolic dysfunction, chronic kidney disease, and coronary artery disease are factors that affected left atrial volume in patients with nonvalvular atrial fibrillation.

Keywords: Atrial fibrillation, three-dimensional echocardiography, left atrial volume

\section{I. ĐẶT VẤN ĐỀ}

Rung nhĩ là một rối loạn nhịp tim thường gặp. Tính đến năm 2010, có khoảng 2,2 triệu người ở Hoa Kỳ đã bị ảnh hưởng bởi bệnh lý này ${ }^{1}$. Dự kiến đến năm 2050, ước tính sẽ có khoảng từ 60 đến 12 triệu người Hoa Kỳ mắc RN, và ở châu Âu đến năm 2060, sẽ có 17,9 triệu người mắc ${ }^{2}$. Rung nhĩ có liên quan đến dịch tễ học với các bệnh khác, chẳng hạn như bệnh van tim, tiểu đường, tăng huyết áp, thừa cân béo phì và hội chứng chuyển hóa và các thành phần của nó, ngưng thở khi ngủ và phản ứng viêm. Điều quan trọng cần lưu ý là rung nhĩ là yếu tố nguy cơ chính của đột quy và cùng với sự phổ biến của nó, thể hiện gánh nặng kinh tế với gia tăng đáng kể tỉ lệ mắc cũng như tử vong. Tî lệ mắc rung nhĩ ở người trẻ ( $<40$ tuổi) là rất thấp $(<1 \%)$ nhưng bệnh sẽ tăng theo độ tuổi và đạt đến tỉ lệ 10 đến $17 \%$ khi bênh nhân trên 80 tuổi. Với sự già hóa của dân số toàn cầu, rung nhĩ được dự báo sẽ trở thành dịch bệnh trong vài năm tới.

Cơ chế sinh lý bệnh của rung nhĩ rất phức tạp, bao gồm: sự khởi phát của các ổ loạn nhịp nhĩ từ các tĩnh mạch phổi, ảnh hưởng của hê thần kinh tự động và vai trò của tái cấu trúc nhĩ trái do các bệnh đồng mắc. Sự tái cấu trúc này thường làm xơ hóa nhĩ trái, gẩy giãn nhĩ trái và từ đó ảnh hưởng đến chức năng nhĩ. Không chỉ đơn thuần là sự thay đổi về hình thái và chức năng, nghiên cứu của các tác giả BouzasMosquera $^{3}$ còn cho thấy kích thước nhĩ trái là yếu tố có khả năng dự báo độc lập nguy cơ tử vong và đột quy ở bệnh nhân (BN) rung nhĩ. Do đó, việc đánh giá và theo dõi kích thước nhĩ trái có ý nghĩa lớn trong thực hành lâm sàng.

Trong đánh giá kích thước nhĩ trái và tái cấu trúc nhĩ trái ở BN rung nhĩ, cần đo thể tích nhĩ trái để lượng giá sự thay đổi buồng nhĩ trái theo mọi hướng. So với siêu âm tim 2D, siêu âm tim 3D (SAT3D) là phương pháp thăm dò giúp phát hiện những thay đổi sớm về thể tích nhĩ trái trong không gian ba chiều theo chu chuyển tim và có giá trị tiên lượng. Các thông số về thể tích và chức năng nhĩ trái trên SAT3D có tương quan chặt chẽ với các thông số đo bằng phương pháp cộng hưởng từ hạt nhân, một phương pháp được coi là tiêu chuẩn vàng trong đánh giá kích thước và chức năng các buồng tim(4,5). Tại Việt Nam, tác giả Đố Ngoc Bích và Nguyễn Thi Thu Hoài đã bước đầu nghiên cứu thể tích nhĩ trái trên SAT3D ở các $\mathrm{BN}$ rung nhĩ cơnn ${ }^{(6)}$. Chưa có nghiên cứu nào tìm hiểu về các yếu tố ảnh hưởng đến kích thước nhĩ trái trên SAT3D ở cả các BN rung nhĩ cơn và rung nhĩ dai dẳng. Do đó, chúng tôi tiến hành nghiên cứu này nhằm mục tiêu:

Tìm hiểu những yếu tố liên quan đến giãn nhĩ trái ở bệnh nhân rung nhĩ không do bệnh van tim trên siêu âm tim 3D

\section{II. ĐỐI TƯƠNGG VÀ PHƯƠNG PHÁP NGHIÊN CỨU}

2.1 Đối tượng nghiên cứu: Nghiên cứu được tiến hành trong 12 tháng từ tháng 07/2020 đến tháng 07/2021 với 80 bệnh nhân được chẩn đoán rung nhĩ, đến khám và điều trị tại Viện Tim Mạch Bệnh Viến Bạch Mai.

Tiêu chuẩn chẩn đoán: Rung nhĩ được chẩn đoán theo khuyến cáo của hội tim mạch học châu Âu $2020^{5}$, trong đó khi ghi điện tâm đồ 12 chuyển đao hoăcc theo dõi điên tâm đồ một chuyển đạo $\geq 30$ giây cho thấy nhịp tim không có sóng $\mathrm{P}$ lặp lại rõ ràng kèm theo khoảng thời gian RR không đều (khi dẫn truyền nhĩ thất không bi tổn thương). Cách chon mẫu: Lấy BN được chẩn đoán xác định rung nhĩ vào nghiên cứu theo trình tự thời gian.

Tiêu chuẩn loại trừ: Các bệnh nhân đã được phẫu thuật tim, có bệnh lý van tim nặng, phẩn suất tống máu giảm (EF<40\%), bệnh cơ tim phì đại, và các bệnh lý nội khoa nặng khác và các bệnh nhân khổng đồng ý tham gia nghiên cứu.

2.2 Phương pháp nghiên cứu: Nghiên cứu mô tả, cắt ngang.

Các bước tiến hành nghiên cứu: Tất cả các $B N$ được giải thích về nghiên cứu và ký cam đoan tham gia nghiên cứu, được hỏi bệnh, thăm khám lâm sàng kỹ lưỡng và làm bệnh án theo mấu, làm một số thăm dò và xét nghiệm sinh hoá, làm ĐTĐ 12 chuyển đạo, làm siêu âm tim $2 \mathrm{D}$ và $3 \mathrm{D}$ theo hướng dẫn của Hội Siêu âm Tim Hoa Kỳ. Tiêu chuẩn đánh giá giãn nhĩ trái khi thể tích nhĩ trái/BSA $>35 \mathrm{ml} / \mathrm{m}^{2}$ theo hướng dẫn của hội Siêu âm Tim Hoa Kỳ $2015^{7}$.

Quy trình SAT3D đánh giá thể tích nhĩ trái:

Địa điểm: Viện Tim Mạch - Bệnh Viện Bạch Mai. Để tiến hành siêu âm tim 3D đánh giá nhĩ 
trái, chúng tôi tiến hành định vị cấu trúc cân thăm dò trên siêu âm 2D. Sau đó, chuyển sang chế độ siêu âm 3D thời gian thực: trên máy siêu âm Epiq CVx của hãng Philips sản xuất tại Hoa Kỳ năm 2019 với đâu dò X5-1 với phân mềm Heart Model. Máy sẽ thu nhận hình ảnh 3D bằng kiểu góc quét rộng $90^{\circ} \times 90^{\circ}$ quan sát hình ảnh khối kim tự tháp (mode full volume) khi người bệnh nín thở. Nếu người bệnh không nín thở được hoặc nhịp tim không đều, sử dụng kiểu thu nhận dữ liệu trong vòng một chu chuyển tim (mode: single-beat) hoặc kiểu góc hẹp (narrowangle). Tiến hành đo đạc các thông số: thể tích nhĩ trái (TT NT) lớn nhất, nhỏ nhất, thể tích nhĩ trái tiền tâm thu trên phân mềm Heart Model.

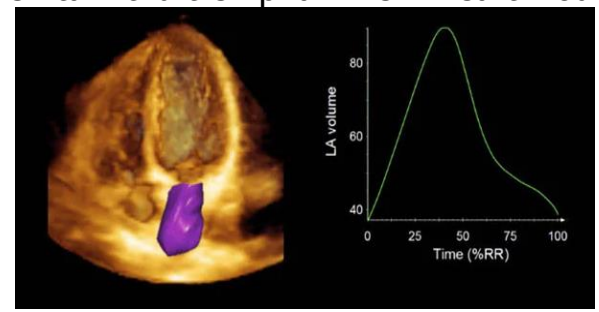

Hinh 1. Minh họa đo thể tích nhĩ trái trên siêu âm tim 306

2.3 Đạo đức nghiên cứu: Nghiên cứu được sự đồng ý của Ban Giám Đốc Bệnh Viện Bạch Mai và Ban Lãnh đạo Viện Tím Mạch Việt Nam.Các bệnh nhân tham gia nghiên cứu đều được giải thích, tư vấn và theo dỗi đây đủ. Toàn bộ thông tin cá nhân của các đối tượng tham gia nghiên cứu đề được giữ bí mật.

2.4 Phương pháp xử lý số liệu: Các số liệu nghiên cứu được lưu trữ và được xử lý bằng các thuật toán thống kê y học trên máy vi tính bằng phần mềm SPSS.25.

\section{KẾT QUẢ NGHIÊN CỨU}

3.1. Đặc điểm chung nhóm nghiên cứu: Trong thời gian 12 tháng từ tháng 07/2020 đến tháng 07/2021, chúng tôi tiến hành nghiên cứu trên 80 bệnh nhân được chẩn đoán rung nhĩ có tuổi từ 56 đến 66, tuổi trung bình $60,7 \pm 4,8$, nam giới (39 bệnh nhân) chiếm $48.8 \%$, nữ giới (41 bệnh nhân) chiếm 51.2\%. Trong đó, có 50\% bệnh nhân có giãn nhĩ trái trên siêu âm, và 50\% không có giãn nhĩ trái trên siêu âm.

Bảng 1. Đặc điểm chung của các BN nghiên cứu

\begin{tabular}{|c|c|c|c|c|}
\hline Đặc điểm lâm sàng & $\begin{array}{c}\text { Giãn nhĩ trái } \\
(n=40)\end{array}$ & $\begin{array}{c}\text { Không giãn NT } \\
(n=40)\end{array}$ & $\begin{array}{l}\text { Chung } \\
(n=80)\end{array}$ & $\mathbf{p}$ \\
\hline \multicolumn{5}{|c|}{ Giới tính } \\
\hline Nam & $23(57,5 \%)$ & $16(40,0 \%)$ & $39(48,8 \%)$ & \multirow{2}{*}{0,117} \\
\hline Nũ & $17(42,5 \%)$ & $24(60,0 \%)$ & $41(51,2 \%)$ & \\
\hline Tuối (năm) & $61,1 \pm 5,4$ & $59,4 \pm 3,4$ & $60,7 \pm 4,8$ & 0,138 \\
\hline BMI $\left(\mathrm{kg} / \mathrm{m}^{2}\right)$ & $24,1 \pm 4,6$ & $23,5 \pm 5,4$ & $23,7 \pm 4,7$ & 0,348 \\
\hline \multicolumn{5}{|c|}{ Yếu tố nguy cơ tim mạch } \\
\hline Tăng huyết áp & $21(52,5 \%)$ & $12(30 \%)$ & $33(41,25 \%)$ & 0,041 \\
\hline Đái tháo đường & $14(35 \%)$ & $7(17,5 \%)$ & $21(26,25 \%)$ & 0,043 \\
\hline Hút thuốc lá & $11(27,5 \%)$ & $8(20 \%)$ & $19(23,75 \%)$ & 0,431 \\
\hline Bệnh mạch vành & $16(40,0 \%)$ & $5(12,5 \%)$ & $21(26,5,75 \%)$ & 0,005 \\
\hline Rối loạn lipid máu & $23(57,5 \%)$ & $26(65 \%)$ & $49(61,25 \%)$ & 0,492 \\
\hline Bênh thân man & $11(27,5 \%)$ & $3(7,5 \%)$ & $14(17,5 \%)$ & 0,019 \\
\hline
\end{tabular}

Nhận xét: So với nhóm không giãn nhĩ trái, nhóm có giãn nhĩ trái có nhiều yếu tố nguy cơ tim mạch như có tăng huyết áp, đái tháo đường, hút thuốc lá, bệnh mạch vành, bệnh thận mạn.

Bảng 2. Đặc điểm của rung nhĩ và điều trị rung nhĩ ở các BN nghiên cứu

\begin{tabular}{|c|c|c|c|c|}
\hline Thông số & $\begin{array}{c}\text { Giãn nhĩ trái } \\
(\mathbf{n = 4 0 )}\end{array}$ & $\begin{array}{c}\text { Không giãn NT } \\
(\mathbf{n = 4 0 )}\end{array}$ & $\begin{array}{c}\text { Chung } \\
\mathbf{( n = 8 0 )}\end{array}$ & $\mathbf{p}$ \\
\hline Nhịp tim (chu kỳ/phút) & $82,3 \pm 7,5$ & $83,6 \pm 4,3$ & $82,6 \pm 7,9$ & 0,256 \\
\hline Rung nhĩ dai dăng & $16(40,0 \%)$ & $4(10,0 \%)$ & $20(25,0 \%)$ & $\mathbf{0 , 0 0 1}$ \\
\hline Thời gian rung nhĩ (tháng) & $83,6 \pm 76,8$ & $56,3 \pm 61,7$ & $71,9 \pm 68,6$ & 0,084 \\
\hline Điểm CHA2DS2VASc & $3,2 \pm 0,4$ & $3,1 \pm 0,6$ & $3,1 \pm 0,4$ & 0,384 \\
\hline \multicolumn{7}{|c|}{ Điêu trị rối loạn nhịp } & $1(2.5 \%)$ & $3(3.75 \%)$ & 0,342 \\
\hline Amiodarone & $2(5 \%)$ & $8(20 \%)$ & $15(18.75 \%)$ & 0,348 \\
\hline Chẹn beta & $7(17.5 \%)$ & $1(2.5 \%)$ & $4(5 \%)$ & 0,457 \\
\hline Digoxin & $3(7.5 \%)$ & $30(75 \%)$ & $58(72.5 \%)$ & 0,612 \\
\hline
\end{tabular}


VIETNAM MEDICAL JOURNAL N01 - DECEMBER - 2021

\begin{tabular}{|c|c|c|c|c|}
\hline \multicolumn{5}{|c|}{ Điêuu trị chống đông } \\
\hline Kháng vitamin K & $6(15 \%)$ & $4(10 \%)$ & $10(12.5 \%)$ & 0,167 \\
\hline NOACs & $7(17.5 \%)$ & $9(22.5 \%)$ & $16(20 \%)$ & 0,234 \\
\hline Không dùng thuốc & $27(67.5 \%)$ & $27(67.5 \%)$ & $54(67.5 \%)$ & 0,454 \\
\hline
\end{tabular}

Nhận xét: Trong nghiên cứu, tỉ lệ rung nhĩ dai dẵng ở nhóm có giãn nhĩ trái lớn hơn có ý nghĩa so với không có giãn nhĩ trái $(40 \%$ so với $10 \%, p<0,05)$. Các đặc điểm khác không có sự khác biệt có ý nghĩa thống kê $(p>0,05)$.

Bảng 3. Đặc điểm trên siêu âm tim 2D và siêu âm tîm 3D ở các BN nghiên cứu

\begin{tabular}{|c|c|c|c|c|}
\hline Thông số & $\begin{array}{c}\text { Giãn nhĩ trái } \\
(n=40)\end{array}$ & $\begin{array}{l}\text { Không giãn } \\
\text { NT }(n=40)\end{array}$ & $\begin{array}{l}\text { Chung } \\
(n=80)\end{array}$ & p \\
\hline \multicolumn{5}{|c|}{ Hình thái và chức năng tâm thu thất trái } \\
\hline ĐK tâm trương (mm) & $45,9 \pm 4,1$ & $46,7 \pm 5,3$ & $45,9 \pm 6,8$ & 0,623 \\
\hline ĐK tâm thu (mm) & $29,8 \pm 4,4$ & $30,5 \pm 4,0$ & $30,4 \pm 5.1$ & 0,835 \\
\hline Thể tích thất trái cuối tâm trương (ml) & $101,1 \pm 22,8$ & $100,4 \pm 23,1$ & $100,2 \pm 19,5$ & 0,722 \\
\hline Thể tích thất trái cuối tâm thu (ml) & $38,7 \pm 12,8$ & $36,3 \pm 10,5$ & $37,6 \pm 10,5$ & 0,271 \\
\hline EF Simpsons & $62, \pm 3,2$ & $63,9 \pm 4,6$ & $62,3 \pm 3,8$ & 0,801 \\
\hline \multicolumn{5}{|c|}{ Chức nằng tâm trương thất trái } \\
\hline RLCN tâm trương & $25(62,5 \%)$ & $22(55 \%)$ & $47(58,74 \%)$ & 0,324 \\
\hline Tỉ lệ E/A (tỉ số) & $0,9 \pm 0,4$ & $0,9 \pm 0,7$ & $09 \pm 0,3$ & 0,412 \\
\hline Tỉ lệ E/e'trung binh (tî số) & $11,2 \pm 3,4$ & $10,5 \pm 2,6$ & $10,3 \pm 2,5$ & 0,126 \\
\hline Vận tốc qua van ba lá & $2,2 \pm 0,2$ & $2,4 \pm 0,4$ & $2,3 \pm 0,5$ & 0,342 \\
\hline \multicolumn{5}{|c|}{ Thất phải } \\
\hline FAC (\%) & $44,1 \pm 6,1$ & $44,3 \pm 2,8$ & $44,2 \pm 5,3$ & 0,342 \\
\hline TAPSE $(\mathrm{mm})$ & $21,3 \pm 2,4$ & $20,6 \pm 1,7$ & $21,4 \pm 1,9$ & 0,245 \\
\hline Áp lực ĐM phổi (mmHg) & $28,2 \pm 4,7$ & $26,0 \pm 3,4$ & $27,6 \pm 2,8$ & 0,052 \\
\hline \multicolumn{5}{|c|}{ Nhĩ trái } \\
\hline ĐK NT trục dọc $\left(\mathrm{mm} / \mathrm{m}^{2}\right)$ & $23,3 \pm 4,7$ & $20,8 \pm 3,2$ & $21,2 \pm 3,5$ & 0,007 \\
\hline TT NT lớn nhất (ml/m²) & $39,1 \pm 5,1$ & $27,1 \pm 4,0$ & $34,7 \pm 2,6$ & 0,000 \\
\hline TT NT nhỏ nhất (ml/m²) & $20,6 \pm 11,0$ & $15,9 \pm 9,0$ & $18,7 \pm 7,4$ & 0,040 \\
\hline TT NT tiền nhĩ thu $\left(\mathrm{ml} / \mathrm{m}^{2}\right)$ & $29,3 \pm 5,4$ & $18,1 \pm 3,5$ & $21,5 \pm 4,6$ & 0,000 \\
\hline TT NT lớn nhất $\left(\mathrm{ml} / \mathrm{m}^{2}\right) 3 \mathrm{D}$ & $49,8 \pm 7,2$ & $32,6 \pm 5,3$ & $44,6 \pm 3,5$ & 0,000 \\
\hline TT NT nhỏ nhất (ml/m²) 3D & $32,2 \pm 7,8$ & $18,4 \pm 5,5$ & $21,4 \pm 6,8$ & 0,000 \\
\hline TT NT tiền nhĩ thu $\left(\mathrm{ml} / \mathrm{m}^{2}\right) 3 \mathrm{D}$ & $43,2 \pm 6,7$ & $30,5 \pm 5,4$ & $34,5 \pm 5,9$ & 0,000 \\
\hline
\end{tabular}

Nhân xét: Hình thái và chức năng thất phải, thất trái giữa 2 nhóm chưa có nhiều sự khác biêtt. Tuy nhiên, các chỉ số về hình thái nhĩ trái (đường kính trục dọc, thể tích đo trên $2 \mathrm{D}$, và $3 \mathrm{D}$ ) ở nhóm giãn nhĩ trái lớn hơn có ý nghĩa so với nhóm không có giãn nhĩ trái.

Bảng 4. Kết quả các yếu tố ảnh hưởng đến kích thước nhĩ trái trên siêu âm 3D

\begin{tabular}{|c|c|c|c|c|c|}
\hline \multirow{3}{*}{ Thông số } & \multicolumn{5}{|c|}{ Thể tích nhĩ trái tối đa 3D - Max LAVI 3D (ml/ m²) } \\
\hline & \multicolumn{3}{|c|}{ Hồi quy đơn biến } & \multicolumn{2}{|c|}{ Hôi quy đa biến } \\
\hline & Hề số $\beta$ & Rho & $\mathbf{p}$ & Hề số $\beta$ & $\mathbf{p}$ \\
\hline Tuổi & $-0,4 \pm 0,3$ & 0,123 & 0,109 & $-0,3 \pm 0,2$ & 0,237 \\
\hline Giới tính (nam) & $-0,3 \pm 0,2$ & 0,023 & 0,325 & $-0,3 \pm 0,1$ & 0,119 \\
\hline Tăng huyết áp & $1,3 \pm 0,9$ & 0,435 & 0,003 & $1,1 \pm 0,4$ & 0,078 \\
\hline Đái tháo đường & $0,8 \pm 0,2$ & 0,432 & 0,015 & $0,8 \pm 0,2$ & 0,079 \\
\hline Bệnh thận mạn & $2,4 \pm 0,9$ & 0,564 & 0,001 & $2,9 \pm 0,3$ & 0,003 \\
\hline Bệnh mạch vành & $2,2 \pm 0,5$ & 0,643 & 0,001 & $2,5 \pm 0,4$ & 0,015 \\
\hline Hút thuốc lá & $2,5 \pm 1,5$ & 0,021 & 0,345 & $1,4 \pm 0,6$ & 0,251 \\
\hline Thời gian rung nhĩ & $1,7 \pm 0,2$ & 0,219 & 0,056 & $0,4 \pm 0,3$ & 0,234 \\
\hline RLCN tâm trương & $2,3 \pm 4,6$ & 0,324 & 0,009 & $2,4 \pm 0,4$ & 0,001 \\
\hline EF Simpsons & $-1,6 \pm 1,2$ & $-0,112$ & 0,523 & $-0,9 \pm 0,6$ & 0,783 \\
\hline
\end{tabular}

Nhận xét: Khi phân tích đơn biến, các yếu tố như tắng huyết áp đái tháo đường, bệnh thận

mạn và bệnh lý mạch vành, rối loạn chức năng tâm trương thất trái là những đặc điểm có liên 
quan với giãn thể tích nhĩ trái trên siêu âm, tương ứng $\beta=1,3 \pm 0,9 \mathrm{ml} / \mathrm{m}^{2}, \beta=0,8 \pm 0,2$ $\mathrm{ml} / \mathrm{m}^{2}, \beta=2,4 \pm 0,9 \mathrm{ml} / \mathrm{m}^{2}, \beta=2,2 \pm 0,5 \mathrm{ml} / \mathrm{m}^{2}$, $\beta=2,3 \pm 4,6 \mathrm{ml} / \mathrm{m}^{2}$. Khi phân tích đa biến, các yếu tố như bệnh thận mạn, bệnh mạch vành, rối loạn chức năng tâm trương thất trái có liên quan với giãn nhĩ trái trên siêu âm tim $3 \mathrm{D}$, tương ứng $\beta=2,9 \pm 0,3 \mathrm{ml} / \mathrm{m}^{2}, \beta=2,4 \pm 0.4 \mathrm{ml} / \mathrm{m}^{2}, \beta=2,4 \pm$ $0.4 \mathrm{ml} / \mathrm{m}^{2}$.

\section{BÀN LUÂ̂N}

Trong cơ chế bệnh sinh phức tạp của rung nhĩ, các nhiêu yếu tố sẽ dẫn đến tình trạng giãn nhî́ trái và đồng thời ngược lại, chính sự giãn nhĩ trái cũng báo hiệu khả năng tái phát, khả năng đột quy, tử vong do biến chứng tắc mạch của rung nhĩ. Do đó, việc theo dõi chính xác sự thay đổi kích thước nhĩ trái có ý nghĩa đặc biệt quan trọng trong thực hành lâm sàng. Cùng như vậy, việc xác định chính xác các yếu tố lâm sàng, cận lâm sàng ảnh hưởng đến kích thước nhĩ trái trong rung nhĩ sẽ giúp các bác sĩ lâm sàng có các chiến lược điều trị dự phòng các yếu tố nguy cơ, từ đó giúp cải thiện tiên lượng chung của những bệnh nhân này. Chính vì điều này, từ năm 2020, Hội Tim Mạch Châu Âu (ESC), bên cạnh 2 yếu tố kinh điển phòng ngừa tắc mạch ( $A$ : anticoagulation), kiểm soát triệu chứng (B: better symptom control), hướng dẫn đã nhấn mạnh đến việc điêu trị các bệnh lý kèm theo (C: comorbidities/Cardiovascular risk factor) ${ }^{5}$. Trong nghiên cứu của chúng tôi, khi so sánh các yếu tố nguy cơ giữa nhóm có và không có giãn nhĩ trái, chúng tôi nhận thấy thể tích nhĩ trái trên siêu âm 3D trên diện tích bề mặt cơ thể có sự khác nhau có ý nghĩa giữa những bệnh nhân có các yếu tố nguy cơ như tăng huyết áp, đái tháo đường, bệnh thận mạn, bệnh lý mạch vành (bảng 1, 2, 3). Khi phân tích về ảnh hưởng của các yếu tố này với sự thay đổi kích thước nhĩ trái, chúng tôi cũng nhận thấy mối liên quan ở mức trung bình giữa tăng huyết áp (rho=0,345), đái tháo đường (rho=0,432), bệnh thận mạn (rho=0,564), bệnh mạch vành ( $(r h o=0,643)$ và̀ rối loạn chức nằng tâm trương thất trái $(r h o=0,324), p<0,05$ (Bảng 4). Khi phân tích đa biến, bệnh thận mạn, bệnh mạch vành và rối loạn chức năng tâm trương thất trái là những yếu tố có liên quan độc lập với kích thước nhĩ trái (Bảng 4).

Ảnh hưởng của tăng huyết áp đến kích thước và chức năng nhĩ trái đã được thông báo trong một số nghiên cứu gần đây. Tại Việt Nam, tác giả Đố Thị Ngọc Bích, Nguyễn Thị Thu Hoài ${ }^{6}$ năm 2020 khi khảo sát chức năng nhĩ trái trên siêu âm tim $2 D$, và $3 D$, tác giả cũng nhận thấy trên những bệnh nhân tăng huyết áp, các chỉ số thể tích nhĩ trái lớn hơn có ý nghĩa thống kê so với nhóm chứng.

Trên thế giới, nghiên cứu của Pawar ${ }^{8}$ và cộng sự năm 2020 cho thấy thể tích nhĩ trái có tướng quan với thời gian khối cơ thất trái, đái tháo đường, rối loạn chức năng tâm trương thất trái. Nghiên cứu của tác giả còn cho thấy với rối loạn chức năng tâm trương thất trái mức độ nhẹ, chỉ số thể tích nhĩ trái chưa cho thấy giá trị tiên lượng, nhưng khi rối loạn chức năng tâm trương thất trái mức độ nặng, chỉ số thể tích nhĩ trái có giá trị tiên lượng lâu dài nguy cơ rung nhĩ, đột quy và tử vong. Nghiên cứu của Filip Zemrak ${ }^{9}$ và cộng sự năm 2017 nhằm đánh giá các yếu tố ảnh hưởng đến kích thước nhĩ trái cũng cho thấy mối liên quan của độ tuổi $\left(\beta=0.2 \mathrm{~mL} / \mathrm{m}^{2}\right.$ trên năm, $P<0.0001)$, nam giới $\left(\beta=-4.2 \mathrm{~mL} / \mathrm{m}^{2}\right.$, $P<0.0001)$, béo phì $\left(\beta=1.3 \mathrm{~mL} / \mathrm{m}^{2}, P<0.01\right)$, người Mỹ gốc Trung Quốc $\left(\left(\beta=-2.6 \mathrm{~mL} / \mathrm{m}^{2}\right.\right.$, $P<0.0001)$. Nghiên cứu cũng cho thây mối quan với bệnh lý mạch vành $\left(\beta=1,4 \mathrm{~mL} / \mathrm{m}^{2}\right)$ và rối loạn chức năng tâm trương thất trái $(\beta=2,4$, $\mathrm{p}<0,001)$, tuy nhiên, lại chưa tìm thấy mối liên quan giữa đái tháo đường và hút thuốc lá. Kết quả này cũng khá tương đồng trong nghiên cứu của chúng tôi.

Như vậy, bằng các cơ chế gián tiếp, thông qua sự cứng lên của cơ tim, rối loạn chức năng tâm trương, điêu này sẽ dẫn đến tình trạng tăng áp lực ở trong nhĩ trái, theo thời gian sẽ làm giãn nhĩ trái và tạo điều kiện thuận lợi cho sự rối loạn chức năng nhĩ trái cững như sự xuất hiện của rung nhĩ. Rõ ràng sự thay đổi áp lực tâm trương thất trái và sự giãn nhĩ trái là hai quá trình có mối quan hệ mật thiết với nhau. Do đó, bên cạnh các yếu tố không thay đổi được như tuổi, giới, chủng tộc, việc điều trị tốt các yếu tố nguy cơ thay đổi được như kiểm soát huyết áp, kiểm soát đường máu, điêu trị tốt bệnh lý mạch vành sẽ góp phần cải thiện chức nắng tim mạch nói chung cũng như kích thước và chức năng nhĩ trái nói riêng.

\section{KẾT LUÂ̂N}

Ở các bệnh nhân rung nhĩ không do bệnh van tim, rối loạn chức năng tâm trương thất trái, bệnh thận mạn, bệnh mạch vành là những yếu tố đi kèm với giãn nhĩ trái trên siêu âm tim 3D.

\section{TÀI LIỆU THAM KHẢO}

1. Lloyd-Jones, D. et al (2010). Executive summary: heart disease and stroke statistics -2010 update: a report from the American Heart Association. Circulation121, 948-954

2. Krijthe, B. P. et al (2013). Projections on the 
number of individuals with atrial fibrillation in the European Union, from 2000 to 2060. European Heart Journal34, 2746-2751.

3. Bouzas-Mosquera, A. et al (2011). Left atrial size and risk for all-cause mortality and ischemic stroke. CMAJ183, E657-E664 .

4. Rodevan, O. et al (1999). Left atrial volumes assessed by three- and two-dimensional echocardiography compared to MRI estimates. Int J Card Imaging15, 397-410.

5. Hindricks, G. et al. 2020 ESC Guidelines for the diagnosis and management of atrial fibrillation developed in collaboration with the European Association for Cardio-Thoracic Surgery (EACTS). European Heart Journal42, 373-498.

6. Đố Ngọc Bích \& Nguyến Thị Thu Hoài (2020). Khảo sát kích thước và chức năng nhĩ trái ở bệnh nhân rung nhĩ cơn trên siêu âm tim 2D và 3D. Tạp chí Tim Mach học Việt Nam23, 87-94.

7. Lang, R. M. et al (2015). Recommendations for Cardiac Chamber Quantification by Echocardiography in Adults: An Update from the American Society of Echocardiography and the European Association of Cardiovascular Imaging. Eur Heart J Cardiovasc Imaging16, 233-271.

8. Pawar, $\mathbf{S}$. The study of the relationship between left atrial (LA) volume and LV diastolic dysfunction and LV hypertrophy: Correlation of LA volume with cardiovascular risk factors (2020). Journal of Women's Health and Reproductive 1

9. Zemrak, F. et al (2017). Left Atrial Structure in Relationship to Age, Sex, Ethnicity, and Cardiovascular Risk Factors. Circulation: Cardiovascular Imaging.

\section{MÔ HİNH BÊNNH TÂT VÀ THỰC TRANG TIẾP CÂN DICH VỤ KHÁM CHỮA BỆnH CỦA NGƯỜI KHIẾM THI TẠI HẦ NộI NĂM 2020}

\section{TÓM TẮT}

Mô hình bệnh tật và thực trạng tiếp cận dịch vụ khám chữa bệnh góp phần quan trọng trong xây dựng kế hoạch chăm sóc sức khỏe cho người khiếm thị một cách toàn diên, giúp công tác phòng chống bênh tật có chiều sâu và có trọng điểm, nâng cao chất lượng chăm sóc sức khỏe. Nghiên cứu mô tả cắt ngang được tiến hành nhằm mô tả mô hình bệnh tật và thực trạng tiếp cân dich vu khám chữa bênh của người khiếm thi tại Hà Nội năm 2020. Có 147 người khiếm thị tham gia vào nghiên cứu. Thông tin được thu thập bằng khám sàng lọc, bộ câu hỏi phỏng vấn và xét nghiệm cận lâm sàng. Kết quả nghiên cứu cho thây tuổi trung bình của NKT là $47,7 \pm 15,8$. Tỉ lệ NKT gặp phải các vấn đề sức khỏe là tương đối cao. Về sức khỏe thể chất có $90,5 \%$ NKT mặc ít nhất một vấn đề răng miệng, 51,7\% NKT có thừa cân. Qua sàng lọc bằng thang điểm DASS21 tỉ lệ lo âu, stress và trầm cảm mức độ nhẹ trở lên lần lượt là $24,5 \%, 14,3 \%$ và $11,6 \%$. Khi bị bệnh NKT đến khám bênh tai bệnh viên quân chiếm tỉ lệ cao nhất 42,9\%. Kết quả cho thấy người khiếm thị tại Hà Nội gặp các vấn đề sức khỏe là tương đối cao, điêu này đặt ra yêu cầu thực tiễn cần quan tâm nhiều hơn đến cổng cuộc chăm sóc sức khỏe cho người khiếm thi.

Từ khóa: Mô hình bệnh tật, tiếp cận, dịch vụ khám chữa bệnh, người khiếm thị

\section{SUMMARY}

\section{THE DISEASE MODEL AND REALITY OF HEALTHCARE ACCESS OF VISUALLY}

*Trường Đại học Y Hà Nội

Chịu trách nhiệm chính: Bùi Thanh Sáng

Email: buithanhsangls95@gmail.com

Ngày nhận bài: 8.9.2021

Ngày phản biên khoa hoc: 26.10.2021

Ngày duyệt bài: 9.11.2021

\section{Bùi Thanh Sáng*, Hồ Thị Kim Thanh*}

IMPAIRED PEOPLE IN HANOI IN 2020

The disease model and reality of healthcare access of the visually impaired make an important contribution to building a comprehensive healthcare plan, helping to deepen and focus on disease prevention and healthcare quality improvement. A descriptive cross-sectional study was conducted to describe the disease model and the reality of healthcare access for the visually impaired in Hanoi in 2020. 147 visually impaired people were participating in this study. The data was collected by screening, interview questions, and laboratory tests. Research results show that the average age of visually impaired people is $47,7 \pm 15,8$. The rate of visually impaired people experiencing health problems is relatively high. Regarding physical health, $90,5 \%$ of visually impaired people have at least one oral disease, $51,7 \%$ of them are overweight. Through screening using the DASS21 scale, the rates of anxiety, stress and depression at mild or higher levels were $24.5 \%, 14.3 \%$ and $11.6 \%$, respectively. When people with disabilities came to the district hospital for medical examination, the highest rate was $42.9 \%$. The results show the visually impaired people in Hanoi have a relatively high level of health problems, which poses a practical requirement to pay more attention to health care for them.

Keywords: Disease model, access, medical examination and treatment services, blind people, visually impaired people, healthcare access, healthcare

\section{I. Đă̆T VẤN ĐỀ}

Sức khỏe là vốn quý nhất của mỗi con người và của toàn xã hội, là tài sản của mỗi quốc gia, mỗi dân tộc trên thế giới. Sức khỏe con người là nhân tố cớ bản quyết định sự phát triển và tồn vong của xã hội [1].

Mô hình bệnh tật của mỗi một quốc gia, một 